\title{
Assessment of knowledge regarding 'essential obstetrics care' among rural pregnant women in Kancheepuram District of Tamil Nadu, India
}

\author{
Gopalakrishnan S.*, Rama R.
}

\begin{abstract}
Department of Community Medicine, Sree Balaji Medical College \& Hospital, Bharath University, Chrompet, Chennai, Tamil Nadu, India
\end{abstract}

Received: 13 August 2015

Accepted: 17 September 2015

*Correspondence:

Dr. Gopalakrishnan S.,

E-mail: drmvkshirsagar@yahoo.co.in

Copyright: ( $)$ the author(s), publisher and licensee Medip Academy. This is an open-access article distributed under the terms of the Creative Commons Attribution Non-Commercial License, which permits unrestricted non-commercial use, distribution, and reproduction in any medium, provided the original work is properly cited.

\begin{abstract}
Background: The first step towards achieving the goals of Reproductive and Child Health programme is to create awareness and educate the pregnant women about salient features of essential \& emergency obstetric care and neonatal care provided. Objectives: To assess the level of knowledge on essential obstetrics care among pregnant women in a rural area.

Methods: This cross sectional study was done in a rural area of Kancheepuram District in Tamil Nadu State, using a sample size of 100 pregnant women, arrived based on the prevalence of knowledge on antenatal care available from literature. The participants were selected by simple random sampling and data collected regarding the knowledge on 'essential obstetrics care', using a structured interview schedule based on the Mother Child Protection card.

Results: About $45 \%$ of the participants had adequate knowledge regarding antenatal care, $46 \%$ had adequate knowledge on danger signs and symptoms of pregnancy, but only $13 \%$ of them had adequate knowledge regarding obstetric care. Knowledge regarding obstetrics care was found to have significant association with the educational status of pregnant mothers.

Conclusions: The knowledge gap found in this study points to the need for re-evaluation of the effectiveness of health education measures given through the health care delivery system and the need for improved / revamped content and quality of health education materials to create better awareness among the pregnant women.
\end{abstract}

Keywords: Antenatal care, Obstetrics care, MCP card, Primary health care

\section{INTRODUCTION}

The health of a country is directly proportional to the health of its women, especially those in the reproductive age group. Hence much focus has been given throughout the world for Maternal and Child Health $(\mathrm{MCH})$ and India is no exception. $\mathrm{MCH}$ care, including family planning services is one among the eight elements of primary health care services provided in India. ${ }^{1}$

During 1997-98 the Reproductive and Child Health [RCH] Programme was launched with one of the key components being essential obstetrics care. The essential obstetrics care intends to provide the basic maternity services to all pregnant women through;

1. Early registration of pregnancy,

2. Provision of minimum three antenatal checkups by ANM/Doctor,

3. Provision of safe delivery at home or in an institution

4. provision of three post natal checkups. $^{2}$

The integration of the $\mathrm{RCH}$ programme with the National Rural and Urban Health Mission has helped to broaden its service outreach and this has helped in substantial 
reduction in the maternal and infant mortality rates in the country.

As part of implementing effectively the components of $\mathrm{RCH}$ services, a joint 'Mother Child Protection' (MCP) card has been developed as a tool, which is a graphical presentation of information pertaining to demographic characteristics, antenatal, intra natal and postnatal mother and infant care details and practices. The MCP card helps the families to learn, understand and follow practices for achieving good health for pregnant women, young mothers and children. The card also acts as a strong medium of monitoring and delivering preventive and curative services of MCH care. ${ }^{3}$

The MCP card has been in use all over the country and is easily understood by mothers as well as health workers with a visual record of mother and child's details. It is kept by the mother and brought to health center during each visit. ${ }^{4}$ Adequate knowledge on obstetrics care by antenatal women will be reflected by their level of knowledge and comprehension of information obtained from MCP card.

Based on this background, this study was planned and carried out to assess the level of knowledge regarding 'essential obstetrics care' among the pregnant women in a rural area of Kancheepuram district.

\section{METHODS}

Study design: This is a community based cross sectional descriptive study done to assess the level of knowledge on 'essential obstetrics care' among rural pregnant women.

Study area and study population: The study area is the field practice area of the rural health training center of our medical college in Kancheepuram district of Tamil Nadu. The study population was the pregnant women residing in the study area at the time of the study period [April - May 2014].

Sample size and sampling technique: A study done by Manju Sharma showed that about $52.1 \%$ of the pregnant women were found to have adequate knowledge on antenatal care. ${ }^{5}$ Based on this, the sample size was calculated using the formula [4 PQ / L2] which came to be 91.9 , at $95 \%$ level with $20 \%$ limit of accuracy. Accounting $10 \%$ for non-response, the final sample size was calculated and rounded of to 100 pregnant women. The list of antenatal women in the area was obtained from the registers of the rural health centers and from among them, 100 pregnant women were selected by simple random sampling.

Data collection: The data collection was carried out by house to house visits using a structured questionnaire which comprised of background information and knowledge regarding essential obstetrics care prepared with reference to the MCP card.

Data analysis: The knowledge of essential obstetrics care was assessed under three components: knowledge regarding

1. Antenatal care,

2. Danger signs during pregnancy

3. Obstetric care.

For each of the component, the correct response to the question was given a score of ' 1 ' and any other response was given ' 0 ' score. The maximum score that could be obtained at the end of the interview was ' 9 ' and a score of above $50 \%$ was taken as adequate knowledge. Data were analyzed using SPSS version 17 software. Student " $t$ " test was used to estimate the statistical significance between mean scores and knowledge regarding the antenatal care.

Ethical clearance and support: The study was carried out after obtaining approval from the Institutional Ethical Committee. Informed consent was obtained prior to the data collection.

\section{RESULTS}

The knowledge regarding antenatal care is given in Table 1. It was observed that $69 \%$ of the participants had correct knowledge regarding the timing of antenatal registration, but $61 \%$ were not aware of the minimum antenatal checkups required.

Moreover, $56 \%$ of the women knew that Blood Pressure should be measured during every visit and $44 \%$ of the participants were unaware of the minimum number of iron and folic acid tablets that has to be taken during pregnancy. The knowledge regarding the correct dosage of Tetanus injection was good [79\%] but knowledge level about the preparations for emergency care was not adequate since $52 \%$ participants were unaware of it.

Table 2 gives the details on the knowledge regarding danger signs and symptoms of pregnancy. It was observed that $45 \%$ of the participants answered pain abdomen as an important danger sign of pregnancy, followed by bleeding per vaginum (34\%). No cases of pallor were reported.

About 26\% were unaware of any danger signs of pregnancy. The knowledge regarding obstetric care is illustrated in Table 3 . This study shows that $75 \%$ of the participants were unaware of the 'five cleans' of home / institution delivery and $77 \%$ do not know the meaning of the Family Planning symbol, the inverted Red Triangle.

The association between mean scores and the background characteristics like level of education, type of family and ability to read is given in Table 4 . 
Table 1: Knowledge regarding antenatal care.

\begin{tabular}{|c|c|c|}
\hline Characteristic & $\begin{array}{l}\text { Frequency } \\
{[n=100]}\end{array}$ & Percentage \\
\hline \multicolumn{3}{|c|}{ Timing of antenatal registration } \\
\hline Correct $\left(1^{\text {st }}\right.$ trimester $)$ & 69 & 69 \\
\hline Wrong & 23 & 23 \\
\hline Do not know & 8 & 8 \\
\hline \multicolumn{3}{|c|}{ Minimum number of antenatal check ups } \\
\hline Correct (4 times) & 37 & 37 \\
\hline Wrong & 61 & 61 \\
\hline Do not know & 2 & 2 \\
\hline \multicolumn{3}{|c|}{$\begin{array}{l}\text { Number of times BP should be measured during } \\
\text { pregnancy }\end{array}$} \\
\hline Correct (during every visit) & 56 & 56 \\
\hline Wrong & 38 & 38 \\
\hline Do not know & 6 & 6 \\
\hline \multicolumn{3}{|c|}{$\begin{array}{l}\text { Minimum number of IFA tablets to be taken during } \\
\text { pregnancy }\end{array}$} \\
\hline Correct (100 tablets) & 38 & 38 \\
\hline Wrong & 44 & 44 \\
\hline Do not know & 18 & 18 \\
\hline \multicolumn{3}{|c|}{ Number of TT injections to be given during pregnancy } \\
\hline Correct (2 injections) & 79 & 79 \\
\hline Wrong & 15 & 15 \\
\hline Do not know & 6 & 6 \\
\hline \multicolumn{3}{|c|}{ Preparation for emergency labour* } \\
\hline Do not know & 52 & 52 \\
\hline Save money & 12 & 12 \\
\hline Arrange for transport & 40 & 40 \\
\hline $\begin{array}{l}\text { Advance identification of } \\
\text { hospital }\end{array}$ & 25 & 25 \\
\hline
\end{tabular}

* Multiple responses: sum of the frequencies will not total to 100

Table 2: Knowledge on danger signs and symptoms of pregnancy.

\begin{tabular}{|ll|l|}
\hline Characteristic & $\begin{array}{l}\text { Frequency } \\
{[\mathbf{n = 1 0 0 ]}}\end{array}$ & Percentage \\
\hline Do not know & 26 & 26 \\
\hline Bleeding per vaginum & 34 & 34 \\
\hline Fever & 14 & 14 \\
\hline Pedal Oedema & 22 & 22 \\
\hline Convulsions/Unconsciousness & 17 & 17 \\
\hline Pain Abdomen & 45 & 45 \\
\hline $\begin{array}{l}\text { Bursting of bag (Rupture of } \\
\text { membrane) }\end{array}$ & 4 & 4 \\
\hline
\end{tabular}

From Figure 1, it can be seen that $46 \%$ of the study participants had adequate knowledge about the danger signs/symptoms of pregnancy while $45 \%$ had adequate knowledge about antenatal care and only $13 \%$ had adequate knowledge on obstetrics care.
Table 3: Knowledge on obstetric care.

\begin{tabular}{|lcc|}
\hline Characteristic & \multicolumn{1}{c|}{$\begin{array}{c}\text { Frequency } \\
{[\mathbf{n = 1 0 0 ]}}\end{array}$} & \begin{tabular}{c} 
Percentage \\
\hline Five Cleans of home $/$ institution
\end{tabular} \\
\hline Do nolivery* Know & 75 & 75 \\
\hline Clean Hands & 8 & 8 \\
\hline Clean Surface & 13 & 13 \\
\hline Clean Blade & 10 & 10 \\
\hline $\begin{array}{l}\text { Clean Umbilical } \\
\text { Cord/Cord tie }\end{array}$ & 18 & 18 \\
\hline $\begin{array}{l}\text { Clean Clothes } \\
\text { Meaning of family planning symbol [inverted } \\
\text { red triangle] when shown }\end{array}$ & \\
\hline Knows & 23 & 23 \\
\hline Do not know & 77 & 77 \\
\hline
\end{tabular}

Table 4: Association between knowledge scores and background characteristics.

\begin{tabular}{|c|c|c|c|c|}
\hline Characteristic & $\begin{array}{l}\text { Number } \\
{[n=100]}\end{array}$ & $\begin{array}{l}\text { Mean } \\
\text { Score }\end{array}$ & $\begin{array}{l}\text { 't' } \\
\text { value }\end{array}$ & $\begin{array}{l}\mathbf{P} \\
\text { value }\end{array}$ \\
\hline \multicolumn{5}{|c|}{ Educational status } \\
\hline$\leq 10^{\text {th }}$ standard & 79 & 30.23 & 4.33 & $0.001 *$ \\
\hline$>10^{\text {th }}$ standard & 21 & 46.21 & & \\
\hline \multicolumn{5}{|c|}{ Ability to read Tamil } \\
\hline Read Tamil & 82 & 35.22 & 2.18 & $0.031 *$ \\
\hline $\begin{array}{ll}\text { Can't } & \text { read } \\
\text { Tamil } & \end{array}$ & 18 & 26.14 & & \\
\hline \multicolumn{5}{|l|}{ Type of family } \\
\hline Nuclear & 49 & 30.85 & 1.6 & $0.048 *$ \\
\hline Joint & 51 & 36.22 & & \\
\hline
\end{tabular}

\section{Average score: Knowledge level (\%)}

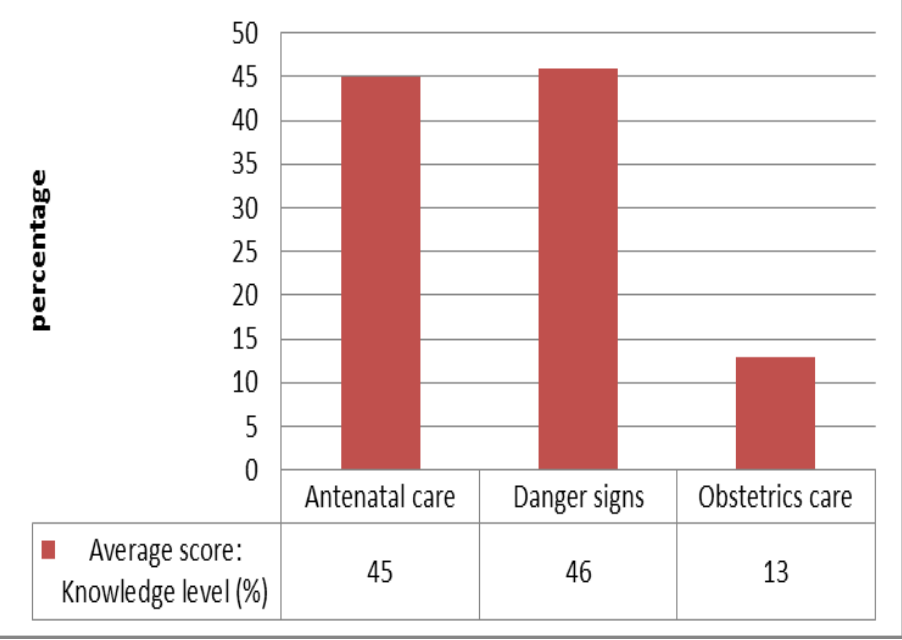

Figure 1: Participants with average level of knowledge for each category. 


\section{DISCUSSION}

An adequate knowledge on antenatal and obstetric care among the pregnant women is a preliminary step towards achieving the goals of $\mathrm{RCH}$ program. The mean age of the study participants was found to be 24.33 years whereas the study done by J. Laishram showed that the mean age of participants to be 29.5 years. ${ }^{6}$ About $57 \%$ were educated up to high school and $82 \%$ of them were able to read and write Tamil.

In this study, $45 \%$ of the participants had adequate knowledge regarding antenatal care, while the study by Manju Sharma shows adequate knowledge level among $51.2 \%$ of the participants. 5 About $38 \%$ of the participants were aware of the number of Iron and folic acid tablets to be taken during pregnancy while $79 \%$ responded correctly about the number of Tetanus Toxoid injections to be given. J. Laishram showed that $34.2 \%$ of the participants were aware of the correct number of Iron and folic acid ablets, which is similar to the findings of this study. ${ }^{6}$

Nearly $52 \%$ of the participants reported that they do not know or have any advance planning or preparation for an emergency labour situation. About $69 \%$ of the participants knew the timing of antenatal registration, but only $37 \%$ knew about the minimum number of antenatal visits. A study on Utilization of Maternal Health Care services done in Kancheepuram district found that $96.6 \%$ of the antenatal mothers received the minimum required antenatal visits and about $99 \%$ deliveries were conducted in an institution, $97.6 \%$ of the mothers were fully immunized with tetanus toxoid while more than $90 \%$ consumed 100 or more IFA tablets. ${ }^{7}$

In this study, $45 \%$ of the participants answered pain abdomen as a danger sign of Pregnancy followed by $34 \%$ saying it is bleeding per vaginum. Kapil Gyawali reported that $42.2 \%$ of the participants felt pain abdomen as an important danger sign of imminent labor. ${ }^{8}$ Overall, $46 \%$ had adequate knowledge regarding the danger signs and symptoms of pregnancy.

Only $13 \%$ of the participants in this study had adequate knowledge regarding the correct components of obstetric care. Nearly $75 \%$ of the pregnant women did not know the importance of the "Five Cleans" to be practiced during conducting delivery at home or an institution to prevent neonatal infections, which is a cause for concern. Studies from Nepal, India and Nigeria had reported that infection accounts for up to $40 \%$ of neonatal deaths, which were mainly due to the inadequate knowledge on clean delivery practices. ${ }^{9-12}$

Analysis of the association of level of knowledge with background characteristics revealed that mother's education played a major role in the knowledge regarding antenatal care $(\mathrm{t}=4.33 ; \mathrm{P}=0.001)$. Those from joint families obtained better scores than nuclear families $(\mathrm{t}$
=1.6; $\mathrm{P}=0.0485)$. Not able to read Tamil also played a significant risk factor for low scoring $(\mathrm{t}=2.18 ; \quad \mathrm{P}=0.03)$. Studies by Laishram and Manna have also revealed similar statistical significant result. ${ }^{6,13}$

This study has shown significant association between the level of education and type of family with respect to the improvement of knowledge on antenatal care among the target group. According to Census 2011, the overall female literacy rate in Tamil Nadu was $74 \%$ and the rural female literacy level of Kancheepuram district was $68.20 \%$. Kancheepuram district has got the distinction of achieving the highest number of institution based deliveries conducted in the whole of Tamil Nadu. ${ }^{7,14}$ Nevertheless, this study reveals a wide gap between the literacy rate and the level of knowledge regarding antenatal /obstetrics care.

A study by Tara M.S revealed that only less than $70 \%$ of the health workers had enough knowledge required to provide health education to the antenatal mothers.15 According to a recent article, the antenatal care in rural India is about $50 \%$ for more than one visit and about $10 \%$ for more than four visits and the availability of skilled attendant at the time of delivery is only about $20 \%$.. This strongly suggests that the coverage of antenatal care in India has to be increased extensively. ${ }^{16}$

Even though Tamil Nadu is in the forefront of delivering the RCH services through the better established health care delivery system, showing better health indicators, the level of knowledge among the target group about the services provided needs to be improved for better utilization of the services provided.

\section{CONCLUSION}

The study has given adequate insights into the gaps and lacunae existing in educating the target groups based on the RCH programme. The study shows that the content and quality of health education materials regarding maternal and child health care, especially regarding essential obstetric care, and imparted through the MCP cards have not adequately reached the target group. Since educational status of the mothers plays a key role in their comprehension and improvement in the level of knowledge, it is mandatory to target all the potential mothers with an opportunity for better education to achieve an acceptable level of education status which will help to bridge the knowledge gap. This will greatly help to reduce the maternal and infant morbidity and mortality rates in the country.

\section{ACKNOWLEDGEMENTS}

This study was carried out with the active participation of the Interns and the field staff of the Rural Health Training Centre attached to the Department. We acknowledge the effort taken by all the Interns and the Field Staff who had participated in the data collection and also for helping to 
organize and carry out this study in the field practice area of the Training Center.

Funding: No funding sources

Conflict of interest: None declared

Ethical approval: The study was approved by the Institutional Ethics Committee

\section{REFERENCES}

1. Park K. Text Book of Preventive and Social Medicine. 22nd edition. Jabalpur India: M/s Banarsidas Bhanot; 2013. Chapter 22, Health Care of the Community; p.828.

2. Park K. Text Book of Preventive and Social Medicine. 22nd edition. Jabalpur India: M/s Banarsidas Bhanot; 2013. Chapter 7, Health Programmes in India; p.415.

3. A Guide for Use of Mother-Child Protection Card for the Community and the Family, AWW, ANM and Sector Supervisors.pg 3. Available from: http://hetv.org/pdf/protection-card/mcp-english.pdf. [Last accessed on 08 Feb 2015].

4. Park K. Textbook of Preventive and Social Medicine. 22nd edition. Jabalpur India: M/s Banarsidas Bhanot; 2013. Chapter 10, Preventive Medicine in Obstetrics, Paediatrics and Geriatrics: p.484.

5. Sharma M, Sharma S. Knowledge, attitude and belief of pregnant women towards safe motherhood in a rural Indian setting. Social Sciences Directory 2012;1(1):13-8.

6. Laishram J, Thounaojam UD. Panmei J, Mukhia S, Devi HS. Knowledge and Practice of Ante-natal Care in an Urban Area. Indian Medical Gazette 2013:101-106.

7. Jha RK, Gopalakrishnan S, Ajitha K, Kuberan D, Rana MM. Utilization of maternal health care services in Kancheepuram District, Tamil Nadu. Indian Journal of Maternal and Child Health 2010;12(4):1-7.

8. Gyawali K, Paneru DP, Jnawali B, Jnawali K. Knowledge and practices on maternal health care among mothers: A Cross sectional study from rural areas of mid-western development region Nepal. J Sci Soc 2013;40:9-13.

9. Chandrashekhar TS, Hary SJ, Binu VS, Sabitri G, Neena C. Home delivery and new-born care practices among urban women in western Nepal: a questionnaire survey. BMC Pregnancy and Childbirth 2006;6(27):6-27.

10. Mohd HK, Najam K, Anees A. Shah MS, Ruby K, Shaik RA. Home Delivery Practices in slums dwellers of Aligarh (UP) India. World Essays J 2013; 1(1):7-10. Available from: http://worldessaysj.com/files_site/paperlist/r_46_13 1011161310.pdf. [Last accessed on 08 Feb 2015].

11. Fetuga T, Ogunlesi F, Adekambi D, Olanrewaju, Olowu A. Comparative analyses of childhood deaths in Sagamu, Nigeria: implications for the fourth MDG. South African Journal of Child Health 2007; 1(3):106-11.

12. Lamina MA. A Survey of Home Delivery and Newborn Care Practices among Women in a Suburban Area of Western Nigeria ISRN Obstetrics and Gynecology 2011; Article ID 983542: 9 pages. doi:10.5402/2011/983542.

13. Manna PK, De D, Gosh D. Knowledge, Attitude and Practices for Antenatal Care and Delivery of the Mothers of Tea Garden in Jalpaiguri and Darjeeling Districts, West Bengal. National Journal of Community Medicine 2011;2(1):4-8.

14. National Health Mission. State Wise Information. Tamil Nadu. Available from: http://nrhm.gov.in/nrhm-in-state/state-wiseinformation/tamil-nadu.html. [Last accessed on 08 Feb 2015].

15. Tara MS. Status of implementation of MCP card for Antenatal, natal and child care services: A study. NIPCCD Regional Centre Bangalore. DCWC Research Bulletin. 2014;18(1):11-2.

16. Prasad R. 'Coverage of antenatal care in India has to be increased'. The Hindu [Internet]. 2014;p13. Available from: http://www.thehindu.com/todayspaper/tp-features/tp-sci-tech-and-agri/coverage-ofantenatal-care-in-india-has-to-beincreased/article6474333.ece. [Last accessed on 08 Feb 2015].

Cite this article as: Gopalakrishnan S, Rama R. Assessment of knowledge regarding 'essential obstetrics care' among rural pregnant women in Kancheepuram District of Tamil Nadu, India. Int J Community Med Public Health 2015;2:526-30. 